\title{
Impact of Age on CD4 Response to Combination Antiretroviral Therapy: A Study in Tehran, Iran
}

\author{
Mehrdad Hasibi', Mahboubeh Hajiabdolbaghi², Shahin Hamzelou', Sara Sardashti ${ }^{*}$, \\ Maryam Foroughi', Zahra Bayat Jozani' ${ }^{1}$, Seyed Ahmad Seyed Alinaghi ${ }^{1}$ \\ ${ }^{1}$ Iranian Research Center for HIV/AIDS (IRCHA), Iranian Institute for Reduction of High Risk Behaviors, Tehran \\ University of Medical Sciences, Tehran, Iran \\ ${ }^{2}$ Department of Infectious Disease, Imam Khomeini Hospital, Tehran University of Medical Sciences, Tehran, \\ Iran \\ Email: *sarasardashti@gmail.com
}

Received 27 February 2014; revised 27 March 2014; accepted 10 April 2014

Copyright (C) 2014 by authors and Scientific Research Publishing Inc.

This work is licensed under the Creative Commons Attribution International License (CC BY). http://creativecommons.org/licenses/by/4.0/

(c) (i) Open Access

\section{Abstract}

Background: This study was undertaken to address the controversy regarding immunologic response to combination antiretroviral therapy (cART) among older patients. Methods: In a crosssectional study all patients attending the HIV Clinic at Imam Khomeini Hospital (Tehran) from 2010 to 2011 were evaluated. Immunologic response was investigated using consecutive CD4+ $T$-cell counts in a one-year interval and outcomes were analyzed for older ( $>=50$ yrs) and younger (<50 yrs) patients using SPSS version 16.0. Results: A total of 714 patients were actively enrolled in the clinic while 24 were 50 years or older, and had initiated ART; a similar random group of younger patients was selected as the control. Hepatitis $C$ was the most prevalent co-infection in both groups. Patients with no serologic evidence of hepatitis B and C had significantly higher CD4+ T-cell counts than HIV/HBV co-infected patients after 12 months $(p=0.04)$. The average increased CD4+ T-cell counts in 6, 9, and 12 months of cART initiation were lower among older patients but the difference was not significant $(50.75$ vs. $123.08 ; p=0.37,132.87$ vs. $710.58 ; p=0.25,271.27$ vs. 500; $p=0.65$ ). Conclusion: About 11\% of the registered HIV-positive patients at our clinic were 50 years or older while their immunologic response to cART showed to be different. Specific needs of older HIV infected patients are highly recommended to be addressed in future treatment and care programs.

\section{Keywords}

HIV, Immunology, Age Groups

\footnotetext{
${ }^{*}$ Corresponding author.
} 


\section{Introduction}

Lack of cure and persistent spread of HIV/AIDS has led to unique challenges in different areas of patient management including the age distribution of infected people [1]. The prevalence and incidence of HIV infection among older people has been reported to be surprisingly high in recent years. It has been estimated that by 2015 , $50 \%$ of people living with HIV will be over 50 years old [2]. The introduction of combined antiretroviral therapy (cART) and low perceived risk of infection in this age group seem to be the major contributors to this rising issue [3] [4].

The increased life-expectancy of HIV-positive patients receiving combined ART has changed HIV/AIDS into a chronic disease. Multiple co-morbidities similar to HIV-negative counterparts, and HIV-related co-infections should all be considered in management of older patients [4].

However, high risk sexual and injection behaviors are perceived to be attributed to the youth and older people who are not even considered in health surveys in many countries [5] [6]. Furthermore, the physiological changes following menopause and use of drugs for erectile dysfunction are also of note when regarding HIV in this group [6]. While older age has been associated with late presentation of HIV and increased mortality, physicians are less likely to offer HIV tests to them [7].

In Middle East and North Africa (MENA) region on the other side, an estimated 55\% increase in the number of new infections highlights the critical existing gaps in prevention and care; therefore, our better understanding of the profile of HIV epidemic in the region through evaluating biologic and epidemiologic features of involved patients is essential [8].

According to official reports, 13\% of people living with HIV/AIDS (PLWHA) in Iran are 45 years or older [9], which seem to have remained substantial in previous years [10]. Sexual transmission seems to have been the main transmission route among those who have been registered while it is undetermined in a major proportion [9] [10].

Considering the most common transmission route being injection drug use in Iran, the role of hepatitis B and C co-infections also needs to be more investigated in different age groups including older patients [10]. HCVRNA levels have known to be higher with older age, and among HIV infected patients, making the investigation of HCV-HIV co-infected older patients even more complicated [11].

Making up a considerable proportion of registered patients besides the increasing sexual transmission of HIV in Iran, older patients need to be more evaluated and considered in health programs. Age-based prevention and treatment protocols are of prominence in future plans.

We conducted the present study with the aim of investigating the clinical and immunological state of older registered patients in the HIV clinic of Imam Khomeini Hospital. For the first time in the region, an investigation on this age group was performed to better define the impact of ART on immunologic response in a cohort when confounding variables including co-infections were evaluated.

\section{Methods}

\subsection{Study Design}

In a retrospective cross-sectional study, all registered patients in the HIV clinic were evaluated using patient records.

\subsection{Study Setting, Participants and Procedures}

We conducted the present study in a major referral HIV Clinic at Imam Khomeini Hospital in Tehran. From all active files, patients presenting their first positive HIV test from September 2009 to August 2012 were considered. The inclusion criteria is as follows: 1) confirmed HIV diagnosis by ELISA and Western Blot; 2) being Iranian; 3) receiving cART (2 NRTIs and 1 PI, 2 NRTIs and 1 NNRTI, or 3 NRTIs); 4) Established follow-up for at least two out-patient entries. To characterize the epidemiological features of the patients, all documents were reviewed.

Demographic, clinical and laboratory data were extracted from patient records. Gender, marital status, history of incarceration, hepatitis co-infections, transmission risk factors, time of first diagnosis, CD4 counts, and ART initiation date were documented. Hepatitis B and C co-infections were based on positive serologic test results.

All patients receiving ART consistently and followed for at least 12 months, were then divided to two groups 
considering their age. For all patients 50 years or older, a random control was considered from the younger age group. The two groups were matched regarding their sex, year of diagnosis, and presence of AIDS defining conditions and ART regimen. CD4 counts since ART initiation measured every three months were documented in structured checklists.

\subsection{Statistical Analysis}

The time of the diagnosis of HIV was considered as time zero. The Mann-Whitney test was used for quantitative findings. All tests were conducted at the $p<0.05$ level of significance using SPSS version 16.0.

\subsection{Ethical Considerations}

Access to the clinic database was approved by the review board of Tehran University of Medical Sciences. Written consent was not required since non-identifiable information previously registered in the database was utilized.

\section{Results}

A total of 714 HIV-positive patients registered in the data system of the Voluntary Counseling and Testing (VCT) Center of Imam Khomeini Hospital were evaluated. Eighty-one patients were 50 years or older, while 24 of them received cART. These 24 patients, considered as the case group, were compared with 24 randomly selected patients younger than 50 years receiving cART; group A and B, respectively.

Male patients were significantly more than female patients in both groups (83.3\% vs. $16.67 \%$ in group A; $70.8 \%$ vs. $29.2 \%$ in group B). Maximum age of patients was 67 years in group A and 49 years in group B. Minimum patient age was 50 years in group A and 26 years in group B. The mean age of the patients was 54.79 year in group A and 37.83 year in group B. Other demographic characteristics and important medical records including incarceration history, employment status, co-infection history, and initial CD4+ T-cell counts are also indicated in Table 1.

Table 1. Demographic characteristic, history of co-infections, and initial CD4 counts of the study population, Tehran, Iran.

\begin{tabular}{|c|c|c|}
\hline \multirow{2}{*}{ Variable } & \multicolumn{2}{|c|}{ Mean or Frequency (\%) } \\
\hline & $\leq \mathbf{5 0}$ yrs & $>\mathbf{5 0}$ yrs \\
\hline Age (year) & 37.83 & 54.79 \\
\hline \multicolumn{3}{|l|}{ Gender } \\
\hline Male & $70.8 \%$ & $83.33 \%$ \\
\hline Female & $29.2 \%$ & $16.67 \%$ \\
\hline \multicolumn{3}{|l|}{ Marital status } \\
\hline Single & $58.3 \%$ & $79.2 \%$ \\
\hline Married & $29.1 \%$ & $12.5 \%$ \\
\hline Divorced & $8.3 \%$ & $4.2 \%$ \\
\hline Widowed & $4.1 \%$ & $4.2 \%$ \\
\hline \multicolumn{3}{|l|}{ Employment } \\
\hline Employed & $88.8 \%$ & $87.5 \%$ \\
\hline Jobless & $11.2 \%$ & $12.5 \%$ \\
\hline History of Incarceration & $8.3 \%$ & $4.1 \%$ \\
\hline History of Injection Drug Use & $20.8 \%$ & $12.5 \%$ \\
\hline \multicolumn{3}{|l|}{ History of Co-Infection } \\
\hline Hepatitis B & $16.7 \%$ & $12.5 \%$ \\
\hline Hepatitis & $45.8 \%$ & $37.8 \%$ \\
\hline Toxoplasmosis & $16.7 \%$ & $8.3 \%$ \\
\hline Initial CD4 Count (cells/microL) & 210.8 & 241.7 \\
\hline
\end{tabular}


Frequency of previous hepatitis B, C, and Toxoplasmosis infections, hepatitis C being the most prevalent in patients of both groups is shown in Table 1. The changing trend of mean CD4+ counts in 3, 6, 9 and 12 months after cART initiation in groups A and B are illustrated in Figure 1 and Figure 2, respectively.

Mean CD4+ counts in patients without hepatitis B or C co-infection were higher than infected patients in 3, 6, 9 and 12 months, while the difference was only significant after 12 months (Table 2). The average increments in CD4+ counts (mean) after 6, 9 and 12 months of cART initiation were lower in group A, but the differences were not statistically significant (Table 3).

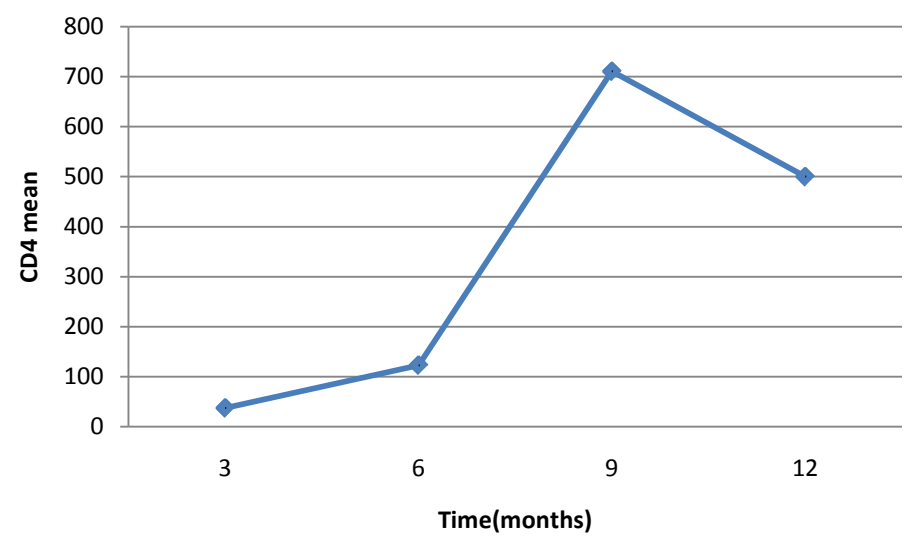

Figure 1. Mean CD4+ counts among patients $<50$ yrs in 3, 6, 9, and 12 months after cART initiation.

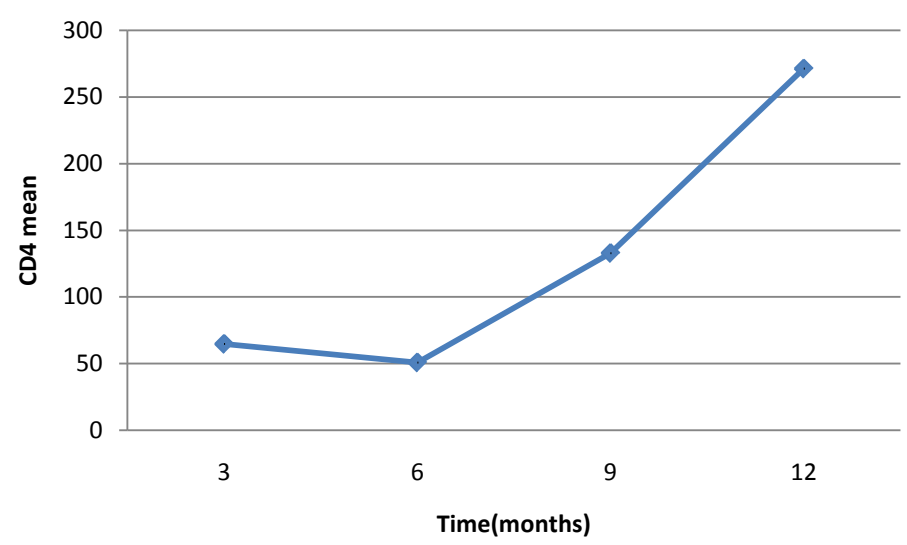

Figure 2. Mean CD4+ counts among patients $>=50$ yrs in 3, 6, 9, and 12 months after cART initiation.

Table 2. Comparisons of serial mean CD4+ counts regarding history of other co-infections in the study population, Tehran, Iran.

\begin{tabular}{ccccc}
\hline Co-infection history & \multicolumn{4}{c}{ Mean CD4 Counts (cell/ micro liters) } \\
\hline Hepatitis B & $\begin{array}{c}\text { 3-month } \\
\text { measurement }\end{array}$ & $\begin{array}{c}\text { 6-month } \\
\text { measurement }\end{array}$ & $\begin{array}{c}\text { 9-month } \\
\text { measurement }\end{array}$ & $\begin{array}{c}\text { 12-month } \\
\text { measurement }\end{array}$ \\
Yes & 25.74 & 16.83 & 28.71 & 51.92 \\
No & 66.66 & 53.59 & 158.91 & 710 \\
Total & 64.79 & 50.76 & 132.87 & 271.28 \\
P-value $^{*}$ & 0.82 & 0.70 & 0.62 & $\mathbf{0 . 0 4}$ \\
Hepatitis C & & & 81.13 & 51.92 \\
Yes & 10.51 & 18.51 & 167.36 & 710 \\
No & 91.81 & 70.91 & & \\
\hline
\end{tabular}




\begin{tabular}{ccccc} 
Continued & & & & \\
\hline Total & 64.71 & 50.76 & 132.87 & 0.69 \\
P-value & 0.31 & 0.32 & & $\mathbf{0 . 0 4}$ \\
Toxoplasmosis & & & 1.25 & - \\
Yes & 4.65 & 7.50 & 165.78 & 271.28 \\
No & 72.01 & 54.36 & 132.87 & 271.28 \\
Total & 64.71 & 50.76 & 0.53 & - \\
P-value & 0.55 & $\mathbf{0 . 0 9}$ & \\
\hline
\end{tabular}

$P$-values $<0.05$ were considered significant.

Table 3. Comparisons of mean CD4+ counts among $\geq 50$ years and $<50$ years old patients after cART initiation, Tehran, Iran.

\begin{tabular}{|c|c|c|}
\hline Months after cART initiation & Mean & P-value ${ }^{*}$ \\
\hline \multicolumn{3}{|l|}{ 3-month measurement } \\
\hline$<50$ yrs & 37.55 & 0.47 \\
\hline$\geq 50$ yrs & 64.70 & \\
\hline \multicolumn{3}{|l|}{ 6-month measurement } \\
\hline$<50$ yrs & 123.08 & 0.37 \\
\hline$\geq 50 \mathrm{yrs}$ & 50.75 & \\
\hline \multicolumn{3}{|l|}{ 9-month measurement } \\
\hline$<50$ yrs & 710.58 & 0.25 \\
\hline$\geq 50$ yrs & 132.87 & \\
\hline \multicolumn{3}{|l|}{ 12-month measurement } \\
\hline$<50$ yrs & 500 & 0.66 \\
\hline$\geq 50$ yrs & 271.27 & \\
\hline
\end{tabular}

$P$-values $<0.05$ were considered significant.

\section{Discussion}

Our study shows that mean CD4+ T-cell count increments after initiation of combination antiretroviral therapy (cART) are lower in older patients. Despite the insignificant difference comparing these two age groups $(>=50$ yrs and $<50$ yrs) in the present study, this trend can be indicative of changes in immunological response to cART among older patients; furthermore, it's relation with their higher rates of disease progression and mortality.

A cohort study from nine African countries, also reports the median gain in CD4+ count was significantly higher at 6 and 12 months after receiving cART in patients younger than 50 years (134 vs. 112 cells $/ \mu 1$ at 6 months; 170 vs. 139 cells/ $\mu$ at 12 months; $\mathrm{P}<0.001$ ) [12].

Torres et al. have also investigated the changes in CD4+ counts after cART initiation in Brazil. They found that the latest CD4 counts were not significantly different in patients $>=50$ years compared to younger patients; however, similar to our study, elderly patients had lower CD4+ nadir [13].

A retrospective study in Greece also showed higher magnitudes of absolute numbers of CD4+ T-cells among patients 50 years or older [14].

Another study on 8846 South African HIV-infected patients over 24 months suggests higher mortality rates among patients $>=50 \mathrm{yrs}$ in the first year after ART initiation, besides the slower immunological response to treatment according to CD4 count measurements; however, when viral suppression achieved, it is proposed that CD4+ count reconstitution may matter less in this age group [14].

We also found that Hepatitis C co-infected patients had lower increased CD4+ counts after 12 months of cART initiation $(\mathrm{p}=0.04)$. Co-morbidities and infections have been reported to be more common among the elderly [14]. Greenbaum et al., despite reporting a higher rate of viral suppression in patients $>=50$ yrs and no changes in immunologic response to antiretroviral treatment in this age group, propose the prominence of comorbidities such as Hepatitis in changes of CD4 counts after cART initiation [4]. 
The high prevalence of hepatitis infection in our patients seems to play a key role in the present findings. Regarding high levels of stigma, male-male sexual contacts and injection drug use are not usually reported by patients; this makes the interpretation of these findings more complex. However, we suppose these findings underscore the role of risk behaviors in immunological response through disease course. The high percentage of individuals with undetermined transmission routes hinder analysis of interactions in the present study, making evaluations of the elderly infected through various transmission routes essential in future studies to shed light on the present assumptions.

A meta-analysis of 13 cohorts has introduced the initial CD4 count as an independent and strong prognostic factor for disease progression [15]. We found the average initial CD4 counts to be similar in both age groups. This excludes the possibility of baseline CD4 count as an influential confounder in differences observed in immunologic response in older patients.

The increasing number of older patients is mainly due to implementation of cART since 1996, while newly infected older patients are underestimated since they are not considered in public health programs [16] [17]. HIV infection has mainly involved younger people in Iran. In our study, only $11 \%$ of patients during study period were 50 years or older. However, this figure is similar to national and international measures. In the latest reports of Iran's Center for Disease Control and Prevention (CDC), 15\% of recognized HIV-infected patients have been 45 years or older [9] [10]. UNAIDS predicts $50 \%$ of HIV-infected patients will be 50 years or older by 2015 [3]. We also anticipate changes in age distribution in our country, which may expect us to consider changes to cART initiation protocols.

Considering the fact that this was a retrospective observational study, we could not measure adherence to treatment. We tried to consider confounder factors and demographic characteristics to minimize sample size effects.

\section{Conclusion}

In summary, we propose that age affects immunologic response to cART although virologic response should be considered simultaneously. We also highlight the role of comorbidities related to the route of transmission of the virus among general population, all of which require further studies on larger sample populations.

\section{Acknowledgements}

We would like to thank all the staff members of the HIV Clinic at Imam Khomeini Hospital for their cooperation during study course. This research received no specific grant from any funding agency in the public, commercial, or not-for-profit sectors. All sources for completion of this study were provided by Tehran University of Medical Sciences.

\section{References}

[1] Adekeye, O.A., Heiman, H.J., Onyeabor, O.S. and Hyacinth, H.I. (2012) The New Invincibles: HIV Screening among Older Adults in the US. PLoS One, 7, e43618. http://dx.doi.org/10.1371/journal.pone.0043618

[2] (2011) Centers for Disease Control and Prevention; HIV Surveillance Report: Diagnoses of HIV Infection and AIDS in the United States and Dependent Areas. http://www.cdc.gov/hiv/pdf/statistics 2011 HIV Surveillance Report vol 23.pdf

[3] (2013) UNAIDS Report on the Global AIDS Epidemic. http://www.unaids.org/en/media/unaids/contentassets/documents/epidemiology/2013/gr2013/UNAIDS_Global_Report 2013_en.pdf

[4] Greenbaum, A.H., Wilson, L.E., Keruly, J.C., Moore, R.D. and Gebo, K.A. (2008) Effect of Age and HAART Regimen on Clinical Response in an Urban Cohort of HIV-Infected Individuals. AIDS, 22, 2331-2339.

[5] WHO (2009) Bulletin of the World Health Organization. http://www.who.int/bulletin/volumes/87/3/09-064030/en/

[6] Nguyen, N. and Holodniy, M. (2008) HIV Infection in the Elderly. Clinical Interventions in Aging, 3, 453-472.

[7] Iwuji, C.C., Churchill, D., Gilleece, Y., Weiss, H.A. and Fisher, M. (2013) Older HIV-Infected Individuals Present Late and Have a Higher Mortality: Brighton, UK Cohort Study. BMC Public Health, 13, 397.

[8] UNAIDS (2013) Regional Report for the Middle East and North Africa (MENA).

[9] Ministry of Health and Medical Education HIV/AIDS Statistics in Iran, Spring 2013. 
[10] Ministry of Health and Medical Education HIV/AIDS Statistics in Iran, Summer 2013.

[11] Uccellini, L., Tseng, F.C., Monaco. A., Shebl, F.M., Pfeiffer, R., Dotrang, M., Buckett, D., Busch, M.P., Wang, E., Edlin, B.R., Marincola, F.M. and O’Brien, T.R. (2012) HCV RNA Levels in a Multiethnic Cohort of Injection Drug Users: Human Genetic, Viral and Demographic Associations. Hepatology, 56, 86-94. http://dx.doi.org/10.1002/hep.25652

[12] Greig, J., Casas, E.C., O’Brien, D.P., Mills, E.J. and Ford, N. (2012) Association between Older Age and Adverse Outcomes on Antiretroviral Therapy: A Cohort Analysis of Programme Data from Nine Countries. AIDS, 26, S31-S37. http://dx.doi.org/10.1097/QAD.0b013e3283558446

[13] Torres, T.S., Cardoso, S.W., de Souza V.L., Marins, L.M., Oliveira, M.S., Veloso, V.G. and Grinsztejn, B. (2013) Aging with HIV: An Overview of an Urban Cohort in Rio de Janeiro (Brazil) across Decades of Life. The Brazilian Journal of Infectious Diseases, 17, 324-331. http://dx.doi.org/10.1016/j.bjid.2012.10.024

[14] Metallidis, S., Tsachouridou, O., Skoura, L., Zebekakis, P., Chrysanthidis, T., Pilalas, D., Bakaimi, I., Kollaras, P., Germanidis, G., Tsiara, A., Galanos, A., Malisiovas, N. and Nikolaidis, P. (2013) Older HIV-Infected Patients-An Underestimated Population in Northern Greece: Epidemiology, Risk of Disease Progression and Death. International Journal of Infectious Diseases, 17, e883-e891. http://dx.doi.org/10.1016/j.ijid.2013.02.023

[15] Mutevedzi, P.C., Lessells, R.J., Rodger, A.J. and Newell, M.L. (2011) Association of Age with Mortality and Virological and Immunological Response to Antiretroviral Therapy in Rural South African Adults. PLoS One, 6, e21795. http://dx.doi.org/10.1371/journal.pone.0021795

[16] Cardoso, S.W., Torres, T.S., Santini-Oliveira, M., Marins, L.M., Veloso, V.G. and Grinsztejn, B. (2013) Aging with HIV: A Practical Review. The Brazilian Journal of Infectious Diseases, 17, 464-479. http://dx.doi.org/10.1016/j.bjid.2012.11.007

[17] Grabar, S., Weiss, L. and Costagliola, D. (2006) HIV Infection in Older Patients in the HAART Era. Journal of Antimicrobial Chemotherapy, 57, 4-7. http://dx.doi.org/10.1093/jac/dki411 